\title{
Cholesterol: The Good, the Bad, and the Ugly - Therapeutic Targets for the Treatment of Dyslipidemia
}

\author{
Nabil A. Elshourbagy Harold V. Meyers Sherin S. Abdel-Meguid \\ Shifa Biomedical Corporation, Malvern, Pa., USA
}

Key Words

Atherosclerosis · Dyslipidemia · Cholesterol

\begin{abstract}
Maintaining cholesterol and triglyceride (TG) levels within healthy limits is critical for decreasing the risk of heart disease. Dyslipidemia refers to the abnormal levels of lipids in the blood, including low high-density lipoprotein cholesterol (HDL-C), also known as good cholesterol, high low-density lipoprotein cholesterol (LDL-C), also known as bad cholesterol, and/or high TG levels that contribute to the development and progression of atherosclerosis. In this article we reviewed some of the current therapeutic targets for the treatment of dyslipidemia, with a primary focus on endothelial lipase and lecithin cholesterol acyl transferase for raising HDL-C, and the proprotein convertase subtilisin-like kexin type 9 (PCSK9), microsomal triglyceride transfer protein, and the messenger RNA of apolipoprotein B for lowering LDL-C. In addition, we reviewed the role of apolipoprotein $\mathrm{Al}$ (apoAI) in raising $\mathrm{HDL}-\mathrm{C}$, where we discuss three apoAl-based drugs under development. These are its mutated dimer (apoAI-Milano), a complex with phospholipids, and a mimetic peptide. Atherosclerosis, mainly because of dyslipidemia, is a leading cause of cardiovascular disease. Regarding the title of this article, the 'good' refers to HDL-C, the 'bad' refers to LDL-C, and the 'ugly' refers to atherosclerosis.
\end{abstract}

(c) 2013 S. Karger AG, Basel

\begin{tabular}{ll}
\hline KARGER & $\begin{array}{l}\text { ( } 2013 \text { S. Karger AG, Basel } \\
1011-7571 / 13 / 0232-0099 \$ 38.00 / 0 \quad \text { Karger }\end{array}$ \\
$\begin{array}{l}\text { E-Mail karger@karger.com } \\
\text { www.karger.com/mpp }\end{array}$ & $\begin{array}{l}\text { This is an Open Access article licensed under the terms of the } \\
\text { Creative Commons Attribution-NonCommercial 3.0 Un- } \\
\text { ported license (CC BY-NC) (www.karger.com/OA-license), } \\
\text { applicable to the online version of the article only. Distribu- } \\
\text { tion permitted for non-commercial purposes only. }\end{array}$
\end{tabular}

\section{Introduction}

Of the estimated 57 million global deaths in 2008, 36 million (63\%) were due to noncommunicable diseases (NCD) [1-3]. The largest proportion of NCD deaths is caused by cardiovascular disease (48\%), followed by cancers $(21 \%)$ and chronic respiratory diseases (12\%). Diabetes is directly responsible for $3.5 \%$ of NCD deaths. Behavioral risk factors, including tobacco use, physical inactivity, an unhealthy diet, and harmful use of alcohol, are estimated to be responsible for about $80 \%$ of coronary heart disease (defined as myocardial infarction, coronary death, or coronary revascularization) and cerebrovascular disease cases [1,4]. Although heart disease is more common among people aged 65 years or older, the number of sudden deaths from heart disease among people aged 15-34 years has increased [5]. The economic impact of cardiovascular diseases on the global health care system continues to grow as the population ages. For example, the total cost of heart disease in the USA alone in 2010 was estimated to be USD 444 billion, including health care expenditures and lost productivity from death and disability [6]. According to the American Heart Association [7], atherosclerosis is a leading cause of cardiovascular disease. A large number of histological studies have shown that atherosclerosis begins in youth, making primary prevention efforts necessary from childhood. By the

Sherin S. Abdel-Meguid

One Great Valley Parkway

Suite 8

Malvern, PA 19355 (USA)

E-Mail sherin@shifabiomedical.com 
time the heart problems are detected, the underlying cause is usually quite advanced, having progressed for decades. Therefore, primary prevention of atherosclerosis must begin in childhood or adolescence [8].

Atherosclerosis is an inflammatory condition resulting from multiple and cumulative risk factors, each of which contributes in varying ways to the development and severity of the condition. Known factors that contribute to the development of atherosclerosis include high low-density lipoprotein cholesterol (LDL-C), low high-density lipoprotein cholesterol (HDL-C), high triglycerides (TG), obesity, a poor diet, physical inactivity, hypertension, genetics, smoking, diabetes mellitus, and the environment $[9,10]$. All of the major lipoprotein classes have an impact in some way on the inflammatory process that leads to the development of atherosclerosis; LDL are proinflammatory, whereas HDL are anti-inflammatory $[9,10]$.

Although it is not possible to control some of the factors that contribute to the development of atherosclerosis, such as genetics and the environment, other factors, such as physical inactivity, smoking, and diet, are controllable. For example, the lower occurrence of cancer and cardiovascular disease in the population around the Mediterranean basin has been linked to the dietary habits of the region [11]. Such a diet is rich in nuts, fruits, vegetables, legumes, whole-wheat bread, fish, and olive oil [11]. Components of the Mediterranean diet are an important source of antioxidant and anti-inflammatory molecules, among which omega-3 fatty acids, oleic acid, and phenolic compounds are prominent [11].

\section{HDL: The Good}

\section{HDL as a Risk Factor for Heart Disease}

HDL plays an important role in removing unesterified (free) cholesterol from peripheral cells and delivering it to the liver through the interaction of HDL with the hepatic HDL receptor. This process is known as reverse cholesterol transport (RCT) $[10,12]$. This is in addition to its antiatherosclerotic, anti-inflammatory, and endothelial protective effects $[1,10]$. Several studies have shown an inverse relationship between HDL blood levels and heart disease [13-15]. It is estimated that $>40 \%$ of coronary events occur in individuals with $\mathrm{HDL}<40 \mathrm{mg} / \mathrm{dl}$. These and several other epidemiological studies emphasize that the risk factor associated with low levels of HDL is totally independent of LDL-C, i.e. no matter how low the LDL level is, a decrease in the HDL level would increase the risk of coronary artery disease.

\section{HDL Is a Primary Participant in RCT}

The importance of RCT for the removal of cholesterol from peripheral tissue for excretion through the liver is well known [16-20]. A critical step in RCT, a multistep process, is maturation of the pre- $\beta_{1}-\mathrm{HDL}$ formed through the acquisition of free cholesterol (FC) and phospholipids (PL) by apolipoprotein AI (apoAI) into a-migrating HDL. The FC is converted into cholesteryl ester (CE) by lecithin cholesterol acyl transferase (LCAT) and migrates into the interior of the HDL particle, thus enabling the transfer of more FC to the cell surface. Plasma pre- $\beta_{1}$-HDL levels have been reported to be increased in patients with coronary artery disease and dyslipidemia. Elevation of the plasma pre- $\beta_{1}$-HDL level is associated with the atherosclerotic phase of coronary artery disease and may be useful for the identification of patients with unstable angina pectoris. High pre- $\beta_{1^{-}}$ HDL concentrations and low LCAT activities are strong positive risk markers for ischemic heart disease and are independent of HDL-C.

\section{HDL Is Anti-Inflammatory}

Atherosclerosis is currently thought to be triggered by initial inflammatory events [21]. A plethora of proinflammatory molecules (e.g. cytokines) in a variety of cell types assist in eventual plaque formation [21]. The formation of oxidized LDL (ox-LDL) amplifies the inflammatory response [22-26]. HDL are anti-inflammatory and inhibit inflammation, as demonstrated in a variety of in vitro and in vivo animal models and human studies $[9,27,28]$, due to their protein constituents, including several paraoxonases [29], platelet-activating factor acetylhydrolase [30], LCAT [31], and glutathione peroxidase [32], as well as apoAI [33]. apoAI has been shown to extract the lipid hydroperoxides [13-hydroperoxyoctadecadienoic acid (HPODE) and 15-hydroperoxyeicosatetraenoic acid (HPETE)] called 'seeding molecules' from ox-LDL [34]. The anti-inflammatory role of HDL is further underscored by studies showing severe degradation of this property during oxidative stress and in the acute phase response to infections [35], in which HDL anti-inflammatory proteins get displaced by proinflammatory molecules such as serum amyloid A [36]. Enzyme systems such as paraoxonases and platelet-activating factor acetylhydrolase are also displaced from HDL $[37,38]$ and, in addition, HDL acquire the proinflammatory protein ceruloplasmin [39]. These changes rapidly shift the HDL profile from RCT supportive and anti-inflammatory to cholesterol accumulative and proinflammatory under such stressful stimuli $[9,40]$. 
Pleiotropic Effects of HDL

HDL may exert several potentially important antiatherosclerotic, anti-inflammatory, antithrombotic, and endothelial protective effects [for a review, see 41]. In particular, the promotion of RCT has been proposed as an antiatherogenic effect of HDL that may promote regression of atherosclerotic lesions [16-20]. Moreover, endothelial dysfunction is thought to play a critical role in the development and progression of atherosclerosis. Several studies have suggested that HDL exerts direct endothelial protective effects, such as stimulation of endothelial production of the antiatherogenic molecule nitric oxide. These studies also suggest that the antioxidant effect of HDL prevents endothelial dysfunction and cell death induced by ox-LDL and tumor necrosis factor-alpha (TNF- $\alpha$ ). HDL inhibits secretion of the potent vasoconstrictor endothelin, oxidation of LDL, adhesion of monocytes to endothelial cells, and thrombosis. Furthermore, it has been observed that HDL may stimulate endothelial repair processes involving mobilization and promotion of the endothelial repair capacity of endothelial progenitor cells. All of the above-mentioned studies have conclusively demonstrated that individuals with low levels of HDL-C have a much greater risk of coronary heart disease outcomes than those without them. In clinical trials involving lowering LDL-C, scientists have studied the effect of HDL-C on atherosclerosis and heart attack rates. They have found that even small increases in HDL-C could reduce the frequency of heart attacks. For each $1 \mathrm{mg} / \mathrm{dl}$ increase in HDL-C, there is a $2-4 \%$ reduction in the risk of coronary heart disease. Although there are no formal National Cholesterol Education Program (NCEP) target treatment levels of $\mathrm{HDL}-\mathrm{C}$, as indicated above, an $\mathrm{HDL}$ level $<40 \mathrm{mg} / \mathrm{dl}$ is considered undesirable and measures should be taken to increase it.

\section{Current Drugs for Raising HDL and Their Limitations}

Much of the current therapeutic efforts, centered on reducing LDL-C levels through the administration of statins [42], do not eliminate the cardiovascular risk, necessitating other approaches to eliminate the residual risk [42], especially for diabetic patients. In addition, limited success has been achieved in providing good therapy for individuals with low HDL-C. Niacin (nicotinic acid) and fibric acid derivatives have been used to increase HDL-C. Niacin decreases LDL-C by about $10 \%$, it increases HDL$\mathrm{C}$ by about $20 \%$, and it decreases TG by about $25 \%$. However, major side effects of niacin therapy have been observed. These include flushing, pruritus, nausea, vomiting, gastrointestinal irritation, and rare hepatotoxicity

Targets for Treating Dyslipidemia
[43]. Fibrates such as gemfibrozil (Lopid) and fenofibrate (TriCor) that are PPARa agonists are known to increase HDL-C by $10-20 \%$ and decrease TG by $20-50 \%$. Side effects of fibrate therapy are dyspepsia, myopathy, and gallstones [44].

One mechanism for increasing HDL is to inhibit the CE transfer protein (CETP), also called plasma lipid transfer protein. CETP, a protein made in the liver, facilitates the transport of CE and TG between the lipoproteins. CETP is also closely involved in the metabolism of cholesterol, $\beta$-lipoproteins, apolipoprotein B (apoB), and apolipoprotein $\mathrm{E}$ (apoE) in type 2 diabetes patients [45]. Partial inhibition of CETP is associated with an increase in HDL-C of up to $100 \%$ and might also decrease the level of LDL. Several recent HDL-raising strategies in clinical trials centered around the CETP inhibitors (torcetrapib and dalcetrapib) were stopped because of death in phase III or a lack of efficacy in reducing cardiovascular events $[46,47]$. The only CETP inhibitor currently in a phase III clinical trial is anacetrapib.

Recently, the US National Institutes of Health (NIH) stopped the AIM-HIGH clinical trial 18 months earlier than planned. The trial revealed that adding high-dose, extended-release niacin to statin treatment in people with heart and vascular disease did not reduce the risk of cardiovascular events, including heart attacks and stroke [48]. The unfortunate failure of the AIM-HIGH clinical trial has caused significant confusion and apprehension in the field since the study showed that the levels of HDL were elevated in patients under treatment. This study contradicted the thousands of in vitro and in vivo studies in laboratory animals and in humans that strongly suggested a host of cardioprotective benefits for high HDL levels. The AIM-HIGH clinical trial was criticized for having a small cohort and inappropriate controls [49]. These data put together, however, suggest that raising HDL levels, although necessary, may not be sufficient for reducing the risk of cardiovascular events, and that higher HDL levels must positively correlate with enhancement of the many beneficial properties of HDL such as cholesterol efflux as a biomarker for HDL functionality.

\section{Endothelial Lipase as a Therapeutic Target for \\ Dyslipidemia}

Endothelial lipase (EL) is a member of the TG lipase gene family [50]. It has both phospholipase and TG lipase activity, but it is more active as a phospholipase than as a TG lipase (phospholipase-to-TG lipase ratio: 1.6) [51]. The link between EL and HDL-C was established following mouse studies suggesting that changes in EL levels 
influence HDL-C metabolism. EL cloned into an adenoviral vector and transfected into COS cells demonstrated that in vitro HDL-C particles are the preferred source of EL substrate for all lipoprotein fractions [51]. Furthermore, a significant increase in plasma HDL-C in mice was observed when the EL gene was knocked out $[52,53]$. Using genetic mouse models with altered levels of EL expression, Ishida et al. [53] reported a strong inverse correlation between HDL levels and EL expression. Furthermore, recent studies showed that targeted EL deletion increases HDL particles with anti-inflammatory properties both in vitro and in vivo [54-58]. This was further supported by the finding that inhibition of EL activity in mice using an EL antibody [59] resulted in a significant increase in HDL-C. Conversely, overexpression of EL in transgenic animals resulted in a significant decrease in HDL-C [52]. These data suggested that EL, at least in mice, plays an important role in HDL-C metabolism. Further genetic association studies in humans demonstrated inverse correlations between EL and HDL-C levels [60-62].

\section{Structure of EL}

Human EL is a protein of about 500 amino acids, with 5 potential $\mathrm{N}$-glycosylation sites. The size of the expressed mature protein is $68 \mathrm{kDa}$. EL has 45,40 , and $27 \%$ amino acid sequence identity with lipoprotein lipase (LPL), hepatic lipase (HL), and pancreatic lipase (PL), respectively. The locations of the 10 cysteine residues, as well as the 19-amino acid lid region, are conserved. The catalytic pocket of EL has the same conserved catalytic triad found in other members of the lipase family. The GXSXG lipase motif surrounding the active site serine is conserved. In addition, there are two conserved potential lipid-binding domains (GLDPAGP and RSFGLSIGIQM), as well as a conserved heparin-binding region. Although the crystal structure of EL is not available, the high sequence identity of EL with other members of the LPL gene family, the conserved disulfide bonds, and other similarities all strongly suggest a similar three-dimensional fold. The only member of this family for which crystal structures are available is PL [63]. Therefore, it is possible to generate a homology model of EL based on the crystal structures of PL and related proteins. The validity of such a model can be easily tested by docking known inhibitors of EL [64].

Unlike LPL and HL, EL is synthesized by endothelial cells and functions at the site where it is synthesized. Furthermore, its tissue distribution is different from that of LPL and HL. As a lipase, EL has primarily phospholipase
A1 activity, and it hydrolyzes effectively and specifically the HDL PL in vitro and ex vivo. Unlike LPL and HL, EL is located in the vascular endothelial cells and its expression is highly regulated by cytokines and physical forces, suggesting that it may play a role in the development of atherosclerosis $[53-58,65]$.

\section{Inhibitors of Human EL}

Recently, GlaxoSmithKline reported a series of EL irreversible inhibitors featuring a sulfonylfuran urea core identified in a high-throughput screening campaign [64]. A lead optimization effort was undertaken to improve the potency and selectivity, leading to inhibitors with improved LPL selectivity (up to 15-fold). O'Connell et al. [66] more recently reported the synthesis of alkyl, aryl, and acyl-substituted phenylboronic acids that inhibit EL, many with near equal potency against both EL and LPL, but several compounds exhibited moderate to good selectivity for EL (up to 42-fold). Clearly, the development of highly EL-selective inhibitors is desired. The discovery of such a molecule would provide a novel means by which to specifically raise HDL-C.

\section{LCAT as a Therapeutic Target for Dyslipidemia}

Overexpression of human LCAT in rabbits and cooverexpression with CETP in mice has shown protection against diet-induced atherogenesis $[67,68]$. Conversely, several mutations in apoAI that impair its LCAT activation are strongly correlated with reduced HDL levels [69]. Physiologically, LCAT binds FC and phosphatidylcholine (PC), transferring the acyl chain at the sn-2 position of $\mathrm{PC}$ to FC, producing CE and lyso-PC. LCAT, an interfacial enzyme [70], functions on the surface of HDL particles. Binding to the HDL surface activates the enzyme, but optimal activity is reached only after association with a cofactor. The most potent activator of LCAT is apoAI, and the mechanism of activation is thought to be similar to that of PL by colipase which forms a 1:1 complex with PL [71]. A three-dimensional structure for LCAT is currently unavailable, although a computational model has been proposed [72]. The model suggests that LCAT has an architecture similar to that of the family of $\alpha / \beta$ hydrolases [73]. Consistent with this hypothesis, mutational experiments that changed the catalytic residues Ser181 [74], His377, and Asp345 [72] into Ala resulted in complete loss of, or severe reductions in, enzyme activity.

Studies with apoAI model peptides have shown that although several molecules bind strongly to HDL and activate LCAT, not all are capable of protection against atherosclerosis. Strong lipid binding is necessary, but not 
sufficient, for protection [75]. It has also been shown recently that apoAI peptides with little or no effect on LCAT in vitro are nevertheless able to increase LCAT activity and HDL-C in apoE-null mice [76]. Furthermore, overexpression of LCAT, even when coexpressed with scavenger receptor class $B$ type I and CETP, failed to increase RCT in macrophages although HDL-C was significantly enhanced [77]. Measurement of the arterial intima media thickness in patients with LCAT genetic deficiencies, as well as other parameters, compared to normal controls, have been reported to both show $[78,79]$ and not show [80] signs of atherosclerosis in the former. On the other hand, it has long been known that mutations in the LCAT gene in humans cause familial LCAT deficiency or fish eye disease $[81,82]$. Several animal models also emphasize the need for a functional LCAT for protection against atherosclerosis. For example, apoE-null mice develop an early atherogenic phenotype, including lesions, concomitant with decreases in LCAT activity [30]; LCAT overexpression is also antiatherogenic in rabbits, in the presence of normal LDL receptors (LDLR) [67], and in mice with LDLR-/- [83]. Conversely, LCAT deficiency increases atherosclerosis in LDLR-/- and apoE-/- double knockout mice [66]. Recent studies in humans have demonstrated that carriers of LCAT gene mutations exhibit increased cardiac atherosclerosis $[84,85]$. In addition, gene transfer using apoAI and LCAT induced cholesterol unloading in complex atherosclerotic lesions in a rabbit model [86]. Recently, small-molecule activators of LCAT have been reported, supporting the potential of this approach [87]. These data strongly suggest that activators of LCAT should be effective in raising HDL levels and treating dyslipidemia.

\section{apoAI}

Another potential therapy for raising HDL is increasing apoAI levels. Experimental data indicate that overexpression of apoAI or infusion apoAI in animal models increases HDL-C levels and decreases atherosclerosis. Several apoAI mimetic peptides are being developed; these include apoAI-Milano [88] (also known as ETC216 or MDCO-216), CER-001 [89], and D-4F [90].

apoAI-Milano is a naturally occurring mutated variant of apoAI. It is a disulfide homodimer resulting from a cysteine for arginine substitution at position 173 on the surface of apoAI. The mutation alters the characteristics of the protein, resulting in apoAI-Milano being functionally more effective than normal apoAI. apoAI-Milano has been shown to significantly reduce cardiovascular disease, even though it causes a reduction in HDL levels and an increase in TG levels [91]. Currently, apoAI-Milano in complex with palmitoyl-oleoyl-phosphatidylcholine (POPC), known as MDCO-216, is being developed by The Medicines Company [92].

CER-001 is a synthetic HDL comprised of recombinant human apoAI complexed with PL and designed to mimic the beneficial properties of natural, nascent pre- $\beta$ HDL [93]. Cerenis Therapeutics reported the completion in May 2010 of a phase I clinical trial of CER-001 for acute coronary syndrome. This randomized, double-blind, placebo-controlled, crossover, single-rising-dose study of 32 healthy dyslipidemic volunteers showed that CER-001 is safe and well tolerated at dosages up to $45 \mathrm{mg} / \mathrm{kg}$ [89]. Cerenis Therapeutics also reported the initiation in March 2011 of a phase II clinical trial for CER-001. This double-blind, randomized, placebo-controlled, safety and efficacy study was designed to assess the ability of CER-001 to regress coronary atherosclerotic plaque as measured by intravascular ultrasound [89].

$\mathrm{D}-4 \mathrm{~F}$ is an orally bioavailable $18-\mathrm{D}$-amino acid apoAI mimetic peptide [94]. Similar to apoAI, D-4F binds nonoxidized lipids but has a structure that enhances its ability to bind and sequester fatty acid hydroperoxides and proinflammatory oxidized PL $[90,95]$. Oral administration of D-4F was shown to improve HDL anti-inflammatory properties in mice and monkeys and dramatically reduced lesions in mouse models of atherosclerosis despite no change in plasma levels of HDL cholesterol [90, 96].

\section{Other Therapeutic Targets}

PPAR agonists, such as the glitazones, are known to have modest HDL-boosting effects although their main action is in reducing insulin resistance. PPAR agonists have been postulated to increase the macrophage cholesterol efflux through increasing ABCA1 and ABCG1 expressions via the PPAR $\gamma / \mathrm{LXR} \alpha$ pathway [97].

\section{LDL: The Bad}

\section{LDL as a Risk Factor for Heart Disease}

LDL carries about $60-70 \%$ of serum cholesterol [98]. It transports cholesterol from the liver to the peripheral tissues. High levels of LDL-C are harmful because it can build up on the arterial walls to initiate the formation of atherosclerotic plaques. Unlike the other lipoproteins, each LDL particle contains mostly one apoB-100 which is responsible for the selective binding of LDL to the LDLR. The binding of LDL to its receptor in the liver is the major 
mechanism used to remove LDL from circulation. Using this mechanism, about $70 \%$ of LDL are removed by the liver, releasing FC [99]. The increase in intracellular cholesterol can affect blood cholesterol levels by inhibiting de novo synthesis of cholesterol, decreasing the synthesis of the LDLR, and increasing the activity of an enzyme that facilitates cholesterol storage [98].

The term hypercholesterolemia usually refers to elevations in the serum LDL level. Primary hypercholesterolemia includes familial hypercholesterolemia (FH), familial ligand-defective apoB, and familial combined hyperlipoproteinemia. Primary hypercholesterolemia is a type IIa dominant disorder that involves mutations in the LDLR gene. Homozygotes usually have a more severe case than heterozygotes. Familial ligand-defective apoB is a type IIa disorder that results in a mutation in apoB-100 that disrupts the binding of LDL to the LDLR, thereby decreasing the metabolism of LDL. Both of these disorders decrease LDLR-mediated endocytosis in the liver and thus increase the serum LDL.

\section{LDL Is Inflammatory}

High levels of LDL, and to a lesser extent very-lowdensity lipoprotein, cause the accumulation of LDL-C in the arterial wall. After LDL accumulates, oxidation of LDL occurs [98]. The ox-LDL can cause extensive damage to the arterial wall, including provocation of an inflammation response, promotion of coagulation, an increase in the activity of some substances that cause vasoconstriction, and inhibition of some substances that cause vasodilation [98]. ox-LDL recruits monocytes which enter the arterial wall and are activated to become macrophages. The macrophages ingest the ox-LDL through the macrophage scavenger receptor to become foam cells or fatty streaks. The foam cells propagate further inflammatory responses, as well as more ox-LDL deposition. Further, microcalcification of the vascular smooth muscle cells takes place, which progresses toward the development of atherosclerosis. Fatty streaks, which are cholesterol-filled macrophages, are the first stage of atherosclerosis formation. Plaques (deposition of fatty substances, cholesterol, calcium, cell components, and others) will then form. Plaques will gradually increase inside the artery, narrowing the arterial walls and thus decreasing the blood flow and oxygen supply to tissues. Plaques are usually kept in check by fibrous caps, which protect and stabilize the lesion. If the plaques rupture, then thrombosis will occur and the damage will spread to other areas, leading to diseases such as ischemic heart disease, myocardial infarction, stroke, peripheral arterial disease, other cardiovascular diseases, and death. Therefore, it is crucial that dyslipidemia, primary or secondary, be treated.

\section{Current Drugs for Lowering LDL and Their}

\section{Limitations}

The primary objective for treating high cholesterol is to lower LDL levels in the blood; the goal is for LDL cholesterol to be $<100 \mathrm{mg} / \mathrm{dl}$ and for very-high-risk individuals $<70 \mathrm{mg} / \mathrm{dl}$ [100]. The current drugs for lowering LDL$\mathrm{C}$, and their limitations, are listed in table 1. The first drugs of choice are the statins. Statins are inhibitors of HMG CoA reductase, a rate-limiting enzyme of the mevalonate pathway of cholesterol synthesis. Fibrates, bile acid-binding resins, and nicotinic acid are also used to lower blood cholesterol levels. Fibrates are PPARa agonists, while bile acid-binding resins bind to bile acids in the intestine and prevent their absorption. To compensate for the loss of bile acids, the liver increases the conversion of cholesterol to bile acids. The conversion of cholesterol to bile acids reduces the cholesterol in the body, and the levels of blood cholesterol drop. In addition, ezetimibe, a lipid-lowering compound that selectively inhibits the intestinal absorption of cholesterol and related phytosterols, although it decreases cholesterol levels, has not been shown to improve cardiovascular disease outcomes. However, it has been reported [106] that ezetimibe monotherapy may be associated with a greater reduction in remnant-like particle cholesterol levels in subjects with metabolic syndrome than in those without it.

There are numerous cholesterol drugs on the market, but they all have limitations as shown in table 1 due to possible adverse effects. Pearson et al. [107] studied 4,888 patients receiving lipid-lowering therapy. They found that only $38 \%$ of these patients were achieving the LDL-C goals set by the NCEP. Their findings indicate that more aggressive treatment of dyslipidemia is needed to attain the goals established by the NCEP guidelines. Such treatment may come from modulation of a pathway other than the mevalonate pathway. One such pathway is the proprotein convertase subtilisin-like kexin type 9 (PCSK9) pathway [108].

\section{Structure of PCSK9}

PCSK9 is a protease that belongs to the subtilisin family of kexin-like proconvertases [109]. It contains a signal sequence of 30 amino acids followed by a prodomain of 122 amino acids, a catalytic domain, and a 279-amino acid cysteine- and histidine-rich C-terminal region known as the $\mathrm{V}$ domain. Unlike other proprotein con- 
vertases, PCSK9 lacks a classical P domain that is required for folding and the regulation of protease activity [110].

The protein is synthesized as a $72-\mathrm{kDa}$ precursor that undergoes zymogen processing between the prodomain and the catalytic domain $[111,112]$. The prodomain (14 $\mathrm{kDa})$ remains bound to the mature protein $(63 \mathrm{kDa})$ as it traverses the secretory pathway. The site of intramolecular cleavage in PCSK9 (Val-Phe-Ala-Gln $\downarrow$ Ser-Ile-Pro) differs from most other proconvertases in that cleavage does not occur after a basic residue [112]. Obtaining a robust in vitro assay for PCSK9 activity has proven difficult and little is known about the requirements for catalytic activity. In contrast to other proprotein convertases, autocatalytic cleavage of PCSK9 does not require calcium [113]. The mature PCSK9 and the associated prodomain both undergo tyrosine sulfation in the late Golgi complex before secretion $[113,114]$. Sulfation of tyrosine residues in other proteins enhances proteinprotein interactions, but the role of this posttranslational modification in PCSK9 has not been defined [109]. Different groups have reported the high-resolution crystal structure of PCSK9 $[109,115]$. The crystal structure reveals that PCSK9 has subtilisin-like pro- and catalytic domains, and a V domain with a novel fold. Although the full-length protein was crystallized, the crystal structure was found to be of the processed enzyme [109], with residues 152 and 153 separated by about $25 \AA$. The core of the prodomain of PCSK9 closely resembles the prodomain of subtilisin, with the C-terminal tetrapeptide of the prodomain (Val-Phe-Ala-Gln) bound in the active site, forming an antiparallel $\beta$ sheet with a strand from the catalytic domain.

\section{PCSK9 as a Therapeutic Target for Dyslipidemia}

The establishment of a link between PCSK9 and cholesterol metabolism was rapidly followed by the discovery that selected mutations in the PCSK9 gene caused autosomal dominant hypercholesterolemia [111], suggesting that the mutations confer a gain of function [116] by increasing the normal activity of PCSK9. This was supported by an experiment in which wild-type and mutant PCSK9 (S127R and F216L) were expressed at high levels in the livers of mice; hepatic LDLR protein levels fell dramatically in mice receiving either the wild-type or the mutant PCSK9 $[113,117]$. No associated reductions in LDLR mRNA levels were observed, indicating that overexpression of PCSK9, whether mutant or wild type, reduces LDLR through a posttranscriptional mechanism.

Targets for Treating Dyslipidemia

Table 1. Current drugs for lowering LDL-C and their limitations

\begin{tabular}{|c|c|c|c|}
\hline Drug class & Drugs & $\begin{array}{l}\text { Possible adverse } \\
\text { effects }\end{array}$ & $\begin{array}{l}\text { Refer- } \\
\text { ences }\end{array}$ \\
\hline $\begin{array}{l}\text { HMG CoA } \\
\text { reductase } \\
\text { inhibitors } \\
\text { (statins) }\end{array}$ & $\begin{array}{l}\text { Atorvastatin } \\
\text { Fluvastatin } \\
\text { Lovastatin } \\
\text { Pitavastatin } \\
\text { Pravastatin } \\
\text { Rosuvastatin } \\
\text { Simvastatin }\end{array}$ & $\begin{array}{l}\text { Liver injury, } \\
\text { memory loss, } \\
\text { diabetes, } \\
\text { muscle damage }\end{array}$ & $100-105$ \\
\hline $\begin{array}{l}\text { Fibrates } \\
\text { (PPARa } \\
\text { agonists) }\end{array}$ & $\begin{array}{l}\text { Clofibrate } \\
\text { Fenofibrate } \\
\text { Gemfibrazil }\end{array}$ & $\begin{array}{l}\text { Dyspepsia, } \\
\text { gallstones, } \\
\text { muscle damage }\end{array}$ & 100 \\
\hline $\begin{array}{l}\text { Bile } \\
\text { acid- } \\
\text { binding } \\
\text { resins }\end{array}$ & $\begin{array}{l}\text { Cholestyramine } \\
\text { Colestipol } \\
\text { Colesevelam }\end{array}$ & $\begin{array}{l}\text { Gastrointestinal } \\
\text { distress, constipation, } \\
\text { decreased absorption } \\
\text { of other drugs }\end{array}$ & 100 \\
\hline $\begin{array}{l}\text { Niacin } \\
\text { (nicotinic } \\
\text { acid) }\end{array}$ & Nicotinic acid & $\begin{array}{l}\text { Flushing, } \\
\text { hyperglycemia, } \\
\text { gout, upper } \\
\text { gastrointestinal } \\
\text { distress, } \\
\text { hepatotoxicity }\end{array}$ & 100 \\
\hline
\end{tabular}

Given that gain-of-function mutations in PCSK9 cause hypercholesterolemia, it was reasonable to ask whether loss-of-function mutations would have the opposite effect and result in hypocholesterolemia. Three loss-offunction mutations in PCSK9 (i.e. Y142X, L253F, and C679X) have been identified in African-Americans [118]. These mutations reduce LDL-C levels by $28 \%$ and have been shown to decrease the frequency of coronary heart disease by $88 \%$. Rashid et al. [119] studied the mechanism of loss-of-function mutations in mice where PCSK9 was inactivated. They reported that these knockout mice showed increased hepatic LDLR protein (but not mRNA), increased clearance of circulating lipoproteins, and reduced plasma cholesterol levels. Structure-function relationship analysis of the naturally occurring mutations in PCSK9 has also provided insight into the mechanism of action of PCSK9. Interestingly, mutations in PCSK9 that have been found to be associated with the greatest reductions in LDL-C plasma levels are those that prevent the secretion of mature PCSK9 by disrupting its synthesis (Y142X), autocatalytic processing (L253F), or folding (C679X) [120]. The Y142X mutation produces no detectable protein because it occurs early in the transcript and is predicted to initiate nonsense-mediated mRNA decay. 
Mutations in the catalytic domain (L253F) interfere with the autocatalytic cleavage of the protein. In cells expressing PCSK9-253F, the amount of mature protein was reduced compared to that in cells expressing PCSK9-WT, suggesting that the mutation inhibits autocatalytic cleavage. The L253F mutation is near the catalytic triad (PCSK9 is a serine protease); therefore, it might disrupt the active site [120]. Inasmuch as autocatalytic cleavage of PCSK9 is required for the export of the protein out of the ER, the L253F mutation delays the transport of PCSK9 from the ER to the cell surface. The nonsense mutation (C679X) in PCSK9, which truncates the protein by 14 amino acids, did not interfere with protein processing, but the mature protein accumulated in the cells and none was secreted, suggesting that the protein is cleaved normally but is misfolded and retained in the ER $[114,120]$.

\section{The PCSK9 Mechanism}

The LDLR is a multidomain protein that consists of a ligand-binding domain, an epidermal growth factor (EGF) precursor homology domain, an O-glycosylated domain, a membrane-spanning domain, and a cytoplasmic domain. Upon LDL binding to the LDLR, the receptor/ligand complex is endocytosed, the ligand is released into the acidic environment of the endosome, and the LDLR is recycled to the cell surface. The LDL then undergoes lysosomal degradation. The binding of PCSK9 to the LDLR on the cell surface causes the eventual degradation of the LDLR. Reduced LDLR levels result in decreased metabolism of LDL, which leads to hypercholesterolemia. Although the mechanism by which PCSK9 causes degradation of the LDLR has not been fully elucidated, it is clear that the protease activity of PCSK9 is not required for LDLR degradation [121, 122]. Li et al. [121] coexpressed the prodomain and the catalytic domain in trans and showed that the secreted PCSK9 was catalytically inactive yet functionally equivalent to the wild-type protein in lowering the cellular LDL uptake and LDLR levels. Similar studies were also reported by McNutt et al. [122]. Furthermore, Zhang et al. [123] mapped PCSK9 binding to the EGF-A repeat of the LDLR and showed that such binding decreases receptor recycling and increases its degradation. They also reported that binding to the EGFA domain of the LDLR was calcium dependent and increased dramatically with a reduction in $\mathrm{pH}$ from 7 to 5.2. Kwon et al. [124] determined the crystal structure of PCSK9 in complex with LDLR-EGF-AB (EGF-A and EGF-B). The structure shows a well-defined EGF-A domain, but the EGF-B domain is disordered and absent from their electron density map. The EGF-A domain binds to the PCSK9 catalytic domain at a site distant from the catalytic site and makes no contact with either the Cterminal domain or the prodomain [125].

\section{Targeting PCSK9}

Several strategies have been proposed for targeting PCSK9 $[126,127]$. mRNA knockdown approaches include the use of antisense oligonucleotides or RNAi. Antisense oligonucleotides administered to mice reduced PCSK 9 expression by $>90 \%$ and lowered plasma cholesterol levels by $53 \%[128,129]$. A single intravenous injection of an RNAi delivered in lipidoid nanoparticles to cynomolgus monkeys reduced plasma PCSK 9 levels by $70 \%$ and plasma LDL-C levels by $56 \%$ [130]. A second approach is to prevent the binding of PCSK9 to the LDLR on the cell surface with a small molecule, a peptide, or an antibody directed against PCSK9. Adding EGF-A fragments to cultured cells inhibits the ability of exogenously added PCSK9 to mediate LDLR degradation. A third approach is to develop small-molecule inhibitors of PCSK9 processing. Despite evidence that the catalytic activity of PCSK9 is not required for LDLR degradation [122], an intracellular inhibitor of PCSK9 catalytic activity should be effective since autocatalytic processing of PCSK9 is required for secretion of the protein from the ER. Following its synthesis, PCSK9 undergoes an autocatalytic cleavage reaction that clips off the prodomain, but the prodomain remains attached to the catalytic domain $[109,115]$. The autocatalytic processing step is required for the secretion of PCSK9 [131], likely because the prodomain serves as a chaperone and facilitates folding. The continued attachment of the prodomain partially blocks the substratebinding pocket of PCSK9 $[109,115]$. McNutt et al. [132] demonstrated that antagonism of secreted PCSK9 increases LDLR expression in HepG2 cells. They showed that an FH-associated LDLR allele (H306Y) that results in a gain-of-function mutation is due to an increase in the affinity of PCSK9 to the LDLR, which would lead to enhanced LDLR destruction and decreased plasma LDL-C clearance. Furthermore, they were able to show elegantly that blocking the secreted PCSK9 with an LDLR (H306Y) subfragment resulted in an increase in the level of LDLR in cultured HepG2 cells. Therefore, PCSK9 acts as a secreted factor to cause LDLR degradation, and a smallmolecule inhibitor that interferes with the autocatalytic process should decrease the amount of mature secreted PCSK9.

The above data strongly suggest that PCSK9 inhibitors should be effective lipid-lowering agents. PCSK9 as a therapeutic target appears to be well validated. This is 
strongly supported by the low plasma LDL-C levels associated with loss-of-function mutations in the PCSK9 gene, which indicate that inhibition of autoprocessing and secretion of PCSK9 through small-molecule treatment should be an effective cholesterol-lowering strategy. In addition, no safety issues associated with inhibition of PCSK9 have been identified. Knockout mice lacking PCSK9 developed normally and had no gross neurological defects [120]. Humans heterozygous for loss-of-function mutations in PCSK9 seem to be healthy [119] and have a normal life span. In addition, human heterozygotes with two inactivating mutations in the PCSK9 gene (Y142X and $\triangle \mathrm{R} 97$ ) and no circulating PCSK9 have very low levels of LDL-C (14-34 mg/dl) and normal hepatic and renal function [133].

The most promising approach thus far for targeting PCSK9 is the use of monoclonal antibodies $(\mathrm{mAb})$ that interfere with the interaction of the PCSK9 catalytic domain with the LDLR on the cell surface [134]. Using nonhuman primates, intravenous infusion of $3 \mathrm{mg} / \mathrm{kg}$ of $\mathrm{mAb} 1$ against the catalytic domain of PCSK9 resulted in a significant reduction in plasma LDL-C of $80 \%$ on day 10 postinjection [135] and, similarly, injection of $3 \mathrm{mg} / \mathrm{kg}$ of J16 mAb in cynomologous monkeys resulted in a $64 \%$ reduction in LDL-C [136]. In addition, a further reduction in LDL-C was observed when these animals were treated with simvastatin (50 $\mathrm{mg} /$ day) and subsequently infused with the J16 antibody (3 mg/kg) [136]. Human clinical trials are underway and the results have been very promising. Pfizer-Rinat RN316 is currently in a phase II clinical trial. The mAb (AMG145) by Amgen was evaluated in a phase I ascending single-dose study which showed that LDL-C was dose-dependently decreased by up to $64 \%$ relative to the placebo when AMG145 was infused intravenously or subcutaneously in healthy subjects [137], with no adverse events. The effect of AMG145 administration will be evaluated in the LAPLACE-TIMI 57 (NCT01380730) clinical trials [138]. In phase I clinical trials, a single dose of Aventis/Regeneron SAR236553/ REGN727 antibody resulted in significant reduction of LDL-C (33-46\%) from baseline when given subcutaneously [139]. SAR236553/REGN727 was also shown to be synergistic with statins [140]. In an 8 -week phase II study of patients with LDL-C levels $\geq 100 \mathrm{mg} / \mathrm{dl}$ on a stable dose of atorvastatin (10 mg/day), SAR236553/REGN727 subcutaneously administered in combination with atorvastatin resulted in a $66 \%$ reduction in LDL-C [7]. In the same study, SAR236553/REGN727 as an add-on to atorvastatin $(80 \mathrm{mg} /$ day) resulted in a decrease of $73 \%$ in comparison with a reduction of $17 \%$ with atorvastatin $(80$ $\mathrm{mg}$ /day) alone. Furthermore, recent phase II clinical data revealed a drop of $40-60 \%$ in LDL-C after subcutaneous administration of the AMG145 PCSK9 $\mathrm{mAb}$ in statin-intolerant patients [141]. In view of the absence of overt toxicity associated with this treatment, a phase III clinical trial has been initiated with $>20,000$ individuals. Completion of this trial is planned for 2015. The anticipated success of the trial should support the concept that inhibition of circulating PCSK9 in combination with statins will result in sharply decreased plasma levels of LDL-C and will be well tolerated. Small-molecule inhibitors are also undergoing early preclinical testing [127].

\section{Other Therapeutic Targets}

Drugs targeting the microsomal triglyceride transfer protein (MTTP) and the messenger RNA for apoB have been approved in the USA. Lomitapide is an MTTP inhibitor that has been approved as an orphan drug for lowering LDL-C in patients with homozygous familial hypercholesterolemia. It is indicated as an adjunct therapy with other lipid-lowering treatments [142]. Mipomersen is an antisense therapeutic that targets the messenger RNA for apolipoprotein. It is a once-weekly subcutaneous injection. It is also a drug for the treatment of patients with homozygous familial hypercholesterolemia, and it is approved as an adjunct therapy with other lipid-lowering treatments [143].

\section{Atherosclerosis: The Ugly}

Endothelial dysfunction in atherosclerosis involves a series of early changes that precede lesion formation. The changes include greater permeability of lipoproteins, upregulation of leukocyte and endothelial adhesion molecules, and migration of leukocytes into the artery wall. Initiation of atherosclerosis involves the accumulation of LDL-C in the subendothelial extracellular space within the arterial wall. Vascular cells oxidize the accumulated LDL to a form that is able to stimulate the recruitment of monocytes that take up the ox-LDL to form macrophages. Further accumulation of the ox-LDL in the subendothelial extracellular space results in the formation of foam cells. Such cells form the earliest visible lesion of atherosclerosis: the fatty streaks. Fatty streak formation in atherosclerosis occurs early with infiltration by lipid-laden monocytes and macrophages along with $\mathrm{T}$ lymphocytes. Later lesions involve a complicated series of steps, including smooth muscle migration, $T$ cell activation, foam cell formation, and platelet adherence and aggregation $[9,10]$. 
Table 2. Novel dyslipidemia drugs

\begin{tabular}{llll}
\hline Drug class & Drug & Company & Status \\
\hline apoAI variant & MDCO-216 & The Medicines Company & Phase I/II \\
apoAI & CER-001 & Cerenis Therapeutics & Phase II \\
MTTP inhibitor & Lomitapide & Aegerion Pharmaceuticals & Marketed \\
apoB mRNA antisense & Mipomersen & Genzyme & Marketed \\
PCSK9 antagonist (monoclonal antibody) & REGN727/SAR236553 & Regeneron/Sanofi & Phase III \\
PCSK9 antagonist (monoclonal antibody) & AMG-145 & Amgen & Lower LDL \\
PCSK9 antagonist (monoclonal antibody) & LGT209 & Novartis & Phase III \\
PCSK9 antagonist (monoclonal antibody) & RN316 & Pfizer & Phase II \\
PCSK9 antagonist (monoclonal antibody) & 1D05 & Merck & Phase II \\
\hline
\end{tabular}

\section{Conclusion}

As stated by the American Heart Association: 'Keeping your cholesterol levels healthy is a great way to keep your heart healthy - and lower your chances of getting heart disease or having a stroke.' Today there are a number of effective drugs for lowering 'bad' cholesterol and decreasing the chance of developing 'ugly' atherosclerotic plaques. Unfortunately, these drugs are not suitable for everyone. Therefore, the development of novel drugs for lowering blood LDL levels is needed and, fortunately, is being pursued today by a number of companies.

Although there are considerable data to suggest that raising 'good' cholesterol levels is necessary to reduce the risk of cardiovascular events, it is now clear that higher HDL levels by themselves are not sufficient and must positively correlate with the enhancement of the many beneficial properties of HDL such as cholesterol efflux as a biomarker of HDL functionality. Therefore, the focus of new drugs aimed at raising HDL levels must now positively correlate the higher HDL levels with HDL functionality.

As indicated above, there are several novel drugs that have been recently marketed and that are being developed to raise HDL and lower LDL. These drugs are summarized in table 2 . With these and other promising earlierstage programs underway, the arsenal of therapeutic tools is expanding to combat and reduce the 'ugly' consequences of dyslipidemia and, ultimately, atherosclerosis.

\section{References}

1 World Health Organization: World Health Statistics 2012. 2012. http://www.who.int/ healthinfo/EN_WHS2012_Full.pdf.

2 World Health Organization: Cause-specific mortality: regional estimates for 2008. 2011. http://www.who.int/healthinfo/global_burden_disease/estimates_regional/en/index. html.

3 World Health Organization: Causes of death 2008: data sources and methods. 2011. http:// www.who.int/healthinfo/global_burden_disease/cod_2008_sources_methods.pdf.

4 World Health Organization: Global health risks: mortality and burden of disease attributable to selected major risks. 2009. http:// www.who.int/healthinfo/global_burden_disease/GlobalHealthRisks_report_full.pdf.

5 Centers for Disease Control and Prevention: Heart disease and stroke prevention: addressing the nation's leading killers. 2006. http:// www.cdc.gov/nccdphp/publications/AAG/ pdf/aag_dhdsp2006.pdf.
6 Centers for Disease Control and Prevention: Heart disease and stroke prevention: addressing the nation's leading killers. 2010. http:// www.cdc.gov/chronicdisease/resources/publications/aag/pdf/2010/dhdsp.pdf.

7 American Heart Association: Guidelines for Primary Prevention of Atherosclerotic Cardiovascular Disease Beginning in Childhood. 2003. http://www.americanheart.org/.

$>8$ Strong JP, Malcom GT, McMahan CA, et al: Prevalence and extent of atherosclerosis in adolescents and young adults: implications for prevention from the Pathobiological Determinants of Atherosclerosis in Youth Study. J Am Med Assoc 1999;281:7277-7235.

>9 Badimon L, Vilahur G: LDL-cholesterol versus HDL-cholesterol in the atherosclerotic plaque: inflammatory resolution versus thrombotic chaos. Ann NY Acad Sci 2012;1254:18-32.

10 Bandeali S, Farmer J: High-density lipoprotein and atherosclerosis: the role of antioxidant activity. Curr Atheroscler Rep 2012;14: 101-107.
1 Pauwels EK: The protective effect of the Mediterranean diet: focus on cancer and cardiovascular risk. Med Princ Pract 2011;20:103111.

12 Lewis GF, Rader DJ: New insights into the regulation of HDL metabolism and reverse cholesterol transport. Circ Res 2005;96:12211232.

13 Bruckert E, Baccara-Dinet M, McCoy F, et al: High prevalence of low HDL-cholesterol in a pan-European survey of 8,545 dyslipidaemic patients. Curr Med Res Opin 2005;21:19271934.

14 Aguilar-Salinas CA, Olaiz G, Valles V, et al: High prevalence of low HDL cholesterol concentrations and mixed hyperlipidemia in a Mexican nationwide survey. J Lipid Res 2001; 42:1298-1307.

$\checkmark 15$ Wilson PW, D’Agostino RB, Levy D, et al: Prediction of coronary heart disease using risk factor categories. Circulation 1998;97: 1837-1847. 
16 Brewer HB Jr: Increasing HDL cholesterol levels. N Engl J Med 2004;350:1491-1494.

$\checkmark 17$ Hausenloy DJ, Yellon DM: Targeting residual cardiovascular risk: raising high-density lipoprotein cholesterol levels. Heart 2008;94:706714.

18 Rothblat GH, Llera-Moya MD, Atger V, et al: Cell cholesterol efflux: integration of old and new observations provides new insights. J Lipid Res 1999;40:781-796.

19 Yokoyama S: Apolipoprotein-mediated cellular cholesterol efflux. Biochim Biophys Acta 1998;1392:1-15.

20 Zannis VI, Cohen J: Old and new players in the lipoprotein system. Curr Opin Lipidol 2000;11:101-103.

21 Epstein SE, Zhou YF, Zhu J: Infection and atherosclerosis: emerging mechanistic paradigms. Circulation 1999;100:e20-e28.

- 22 Hessler JR, Robertson AL Jr, Chisolm GM 3rd: LDL-induced cytotoxicity and its inhibition by HDL in human vascular smooth muscle and endothelial cells in culture. Atherosclerosis 1979;32:213-229.

23 Colles SM, Maxson JM, Carlson SG, et al: Oxidized LDL-induced injury and apoptosis in atherosclerosis: potential roles for oxysterols. Trends Cardiovasc Med 2001;11: 131-138.

24 Boudjeltia KZ, Legssyer I, Van Antwerpen P, et al: Triggering of inflammatory response by myeloperoxidase-oxidized LDL. Biochem Cell Biol 2006;84:805-812.

25 Martin-Fuentes P, Civeira F, Recalde D, et al: Individual variation of scavenger receptor expression in human macrophages with oxidized low-density lipoprotein is associated with a differential inflammatory response. J Immunol 2007;179:3242-3248.

26 Galkina E, Ley K: Immune and inflammatory mechanisms of atherosclerosis. Annu Rev Immunol 2009;27:165-197.

27 Murphy AJ, Woollard KJ: High density lipoprotein - a potent inhibitor of inflammation. Clin Exp Pharmacol Physiol 2010;37:710718.

28 Kontush A, Chapman MJ: Antiatherogenic small, dense HDL - guardian angel of the arterial wall? Nat Clin Pract Cardiovasc Med 2006;3:144-153.

29 Mackness MI, Arrol S, Durrington PN: Paraoxonase prevents accumulation of lipoperoxides in low-density lipoprotein. FEBS Lett 1991;286:152-154.

- 30 Stafforini DM, McIntyre TM, Prescott SM: Platelet-activating factor acetylhydrolase from human plasma. Methods Enzymol 1990; 187:344-357.

-31 Forte TM, Subbanagounder G, Berliner JA, et al: Altered activities of anti-atherogenic enzymes LCAT, paraoxonase, and platelet-activating factor acetylhydrolase in atherosclerosis-susceptible mice. J Lipid Res 2002;43:477485.
Navab M, Berliner JA, Subbanagounder G, et al: HDL and the inflammatory response induced by LDL-derived oxidized phospholipids. Arterioscler Thromb Vasc Biol 2001;21: 481-488.

33 Navab M, Anantharamaiah GM, Reddy ST, et al: Human apolipoprotein A-I and A-I mimetic peptides: potential for atherosclerosis reversal. Curr Opin Lipidol 2004;15:645649.

34 Navab M, Hama SY, Anantharamaiah GM, et al: Normal high density lipoprotein inhibits three steps in the formation of mildly oxidized low density lipoprotein: steps 2 and 3. J Lipid Res 2000;41:1495-1508.

-35 Jahangiri A, de Beer MC, Noffsinger V, et al: HDL remodeling during the acute phase response. Arterioscler Thromb Vasc Biol 2009; 29:261-267.

36 Kontush A, Chapman MJ: Functionally defective high-density lipoprotein: a new therapeutic target at the crossroads of dyslipidemia, inflammation, and atherosclerosis. Pharmacol Rev 2006;58:342-374.

37 Van Lenten BJ, Hama SY, de Beer FC, et al: Anti-inflammatory HDL becomes pro-inflammatory during the acute phase response: loss of protective effect of HDL against LDL oxidation in aortic wall cell cocultures. J Clin Invest 1995;96:2758-2767.

38 Tsironis LD, Katsouras CS, Lourida ES, et al: Reduced PAF-acetylhydrolase activity associated with $\mathrm{Lp}(\mathrm{a})$ in patients with coronary artery disease. Atherosclerosis 2004;177:193201.

39 Sampietro T, Neglia D, Bionda A, et al: Inflammatory markers and serum lipids in idiopathic dilated cardiomyopathy. Am J Cardiol 2005;96:1718-1720.

40 Khovidhunkit W, Kim M-S, Memon RA, et al: Thematic review series: the pathogenesis of atherosclerosis - effects of infection and inflammation on lipid and lipoprotein metabolism mechanisms and consequences to the host. J Lipid Res 2004;45:1169-1196.

41 Nofer JR, Kehrel B, Fobker M, et al: HDL and arteriosclerosis: beyond reverse cholesterol transport. Atherosclerosis 2002;161:1-16.

42 Nicholls SJ, Tuzcu EM, Sipahi I, et al: Statins, high-density lipoprotein cholesterol, and regression of coronary atherosclerosis. JAMA 2007;297:499-508.

43 Thomson Micromedex: Niacin. http://www. thomsonhc.com (accessed June 16, 2008).

44 Thomson Micromedex: Gemfibrozil. http:// www.thomsonhc.com (accessed June 16, 2008).

45 Inukai Y, Ito K, Hara K, et al: Serum cholesteryl ester transfer protein concentrations are associated with serum levels of total cholesterol, beta-lipoprotein and apoproteins in patients with type 2 diabetes mellitus. Med Princ Pract 2007;16:367-372.

46 Joy TR, Hegele RA: The failure of torcetrapib: what have we learned? Br J Pharmacol 2008; 154:1379-1381.
47 Husten L: Roche terminates development of CETP inhibitor dalcetrapib. Forbes, May 7 , 2012.

48 National Institutes of Health: AIM-HIGH trial (NCT00120289). 2011. www.clinicaltrials. gov.

49 American Heart Association: RTP-UPDATE 2-US study doubting niacin's heart effects challenged. 2011. http://www.reuters.com/ article/2011/11/17/heart-niacin/idUSN1E7AG1JC20111117.

50 Jaye M, Lynch K, Krawiec J, et al: A novel endothelial-derived lipase that modulates HDL metabolism. Nat Genet 1999;21:424-428.

51 McCoy MG, Sun GS, Marchadier D, et al: Characterization of the lipolytic activity of endothelial lipase. J Lipid Res 2002;43:921-929.

$52 \mathrm{Ma} \mathrm{K}$, Cilingiroglu M, Otvos JD, et al: Endothelial lipase is a major genetic determinant for high-density lipoprotein concentration, structure, and metabolism. Proc Natl Acad Sci USA 2003;100:2748-2753.

53 Ishida T, Choi S, Kundu RK, et al: Endothelial lipase is a major determinant of HDL level. J Clin Invest 2003;111:347-355.

54 Hara T, Ishida T, Kojima Y, et al: Targeted deletion of endothelial lipase increases HDL particles with anti-inflammatory properties both in vitro and in vivo. J Lipid Res 2011;52: 57-67.

55 Yasuda T, Ishida T, Rader DJ: Update on the role of endothelial lipase in high-density lipoprotein metabolism, reverse cholesterol transport, and atherosclerosis. Circ J 2010;74: 2263-2270.

56 Otera H, Ishida T, Nishiuma T, et al: Targeted inactivation of endothelial lipase attenuates lung allergic inflammation through raising plasma HDL level and inhibiting eosinophil infiltration. Am J Physiol Lung Cell Mol Physiol 2009;296:L594-L602.

57 Yasuda T, Hirata K, Ishida T, et al: Endothelial lipase is increased by inflammation and promotes LDL uptake in macrophages. J Atheroscler Thromb 2007;14:192-201.

58 Ishida T, Choi S, Kundu R, et al: Endothelial lipase modulates susceptibility to atherosclerosis in apolipoprotein-E-deficient mice. J Biol Chem 2004;279:45085-45092.

59 Jin W, Millar JS, Broedl U, et al: Inhibition of endothelial lipase causes increased HDL cholesterol levels in vivo. J Clin Invest 2003;111: 357-362.

60 Hutter CM, Austin MA, Farin FM, et al: Association of endothelial lipase gene (LIPG) haplotypes with high-density lipoprotein cholesterol subfractions and apolipoprotein AI plasma levels in Japanese Americans. Atherosclerosis 2006; $185: 78-86$

61 Badellino KO, Wolfe ML, Reilly MP, et al: Endothelial lipase concentrations are increased in metabolic syndrome and associated with coronary atherosclerosis. PLoS Med 2006; 3:e22. 
62 Cox L, Birnbaum S, Mahaney M, et al: Identification of promoter variants in baboon endothelial lipase that regulate high-density lipoprotein cholesterol levels. Circulation 2007; 116:1185-1195.

63 Winkler F, D’Arcy A, Hunziker W: Structure of human pancreatic lipase. Nature 1990;343: 771-774.

64 Goodman KB, Bury MJ, Cheung M, et al: Discovery of potent, selective sulfonylfuran urea endothelial lipase inhibitors. Bioorg Med Chem Lett 2009; 19:27-30.

65 Choi SY, Hirata K, Ishida T, et al: Endothelial lipase: a new lipase on the block. J Lipid Res 2003;43:1765-1769.

- 66 O'Connell DP, LeBlanc DF, Cromley D, et al: Design and synthesis of boronic acid inhibitors of endothelial lipase. Bioorg Med Chem Lett 2012;22:1397-1401.

67 Brousseau ME, Kauffman RD, Herderick EE, et al: LCAT modulates atherogenic plasma lipoproteins and the extent of atherosclerosis only in the presence of normal LDL receptors in transgenic rabbits. Arterioscler Thromb Vasc Biol 2000;20:450-458.

68 Furbee JW Jr, Sawyer JK, Parks JS: Lecithin: cholesterol acyltransferase deficiency increases atherosclerosis in the low density lipoprotein receptor and apolipoprotein $\mathrm{E}$ knockout mice. J Biol Chem 2002;277:3511-3519.

-69 Sorci-Thomas MG, Thomas MJ: The effects of altered apolipoprotein A-I structure on plasma HDL concentration. Trends Cardiovasc Med 2002;12:121-128.

70 Lowe ME: The triglyceride lipases of the pancreas. J Lipid Res 2002;43:2007-2016.

71 Sarda L: Pancreatic lipase; in Alberghina L, Schmid R, Verger R (eds): Lipases: Structure Mechanism and Genetic Engineering. New York, Springer, 1991.

72 Peelman F, Vinaimont N, Verhee A, et al: A proposed architecture for lecithin cholesterol acyl transferase (LCAT): identification of the catalytic triad and molecular modeling. Protein Sci 1998;7:587-599.

73 Ollis DL, Cheah E, Cygler M, et al: The alpha/ beta hydrolase fold. Protein Eng 1992;5:197211.

74 Francone OL, Fielding CJ: Structure-function relationships in human lecithin:cholesterol acyltransferase: site-directed mutagenesis at serine residues 181 and 216. Biochemistry 1991;30:10074-10077.

-75 Anantharamaiah GM, Mishra VK, Garber DW, et al: Structural requirements for antioxidative and anti-inflammatory properties of apolipoprotein A-I mimetic peptides. J Lipid Res 2007;48:1915-1923.

76 Chen X, Burton C, Song X, et al: An apoA-I mimetic peptide increases LCAT activity in mice through increasing HDL concentration. Int J Biol Sci 2009;5:489-499.

-77 Tanigawa H, Billheimer JT, Tohyama J, et al: Lecithin: cholesterol acyltransferase expression has minimal effects on macrophage reverse cholesterol transport in vivo. Circulation 2009;120:160-169.
8 Hovingh GK, de Groot E, van der Steeg W, et al: Inherited disorders of HDL metabolism and atherosclerosis. Curr Opin Lipidol 2005; 16:139-145.

79 Scarpioni R, Paties C, Bergonzi G: Dramatic atherosclerotic vascular burden in a patient with familial lecithin-cholesterol acyltransferase (LCAT) deficiency. Nephrol Dial Transplant 2008;23:1074, author reply 10741075.

80 Calabresi L, Favari E, Moleri E, et al: Functional LCAT is not required for macrophage cholesterol efflux to human serum. Atherosclerosis 2009;204:141-146.

81 Jonas A: Lecithin cholesterol acyltransferase. Biochim Biophys Acta 2000;1529:245-256.

82 Miida T, Zhang B, Obayashi K, et al: T13M mutation of lecithin-cholesterol acyltransferase gene causes fish-eye disease. Clin Chim Acta 2004;343:201-208.

83 Mertens A, Verhamme P, Bielicki JK, et al: Increased low-density lipoprotein oxidation and impaired high-density lipoprotein antioxidant defense are associated with increased macrophage homing and atherosclerosis in dyslipidemic obese mice: LCAT gene transfer decreases atherosclerosis. Circulation 2003; 107:1640-1646.

84 Duivenvoorden R, Holleboom AG, van den Bogaard B, et al: Cholesterol acyltransferase gene mutations have accelerated atherogenesis as assessed by carotid 3.0-T magnetic resonance imaging. J Am Coll Cardiol 2011;58: 2481-2487.

85 Duivenvoorden R, Holleboom AG, van den Bogaard B, et al: Carriers of lecithin cholesterol acyltransferase gene mutations have accelerated atherogenesis as assessed by carotid 3.0-T magnetic resonance imaging (corrected). J Am Coll Cardiol 2012;59:196.

86 Van Craeyveld E, Lievens J, Jacobs F, et al: Apolipoprotein A-I and lecithin:cholesterol acyltransferase transfer induce cholesterol unloading in complex atherosclerotic lesions. Gene Ther 2009;16:757-765.

87 Chen Z, Wang SP, Krsmanovic ML, et al: Small molecule activation of lecithin cholesterol acyltransferase modulates lipoprotein metabolism in mice and hamsters. Metabolism 2012;61:470-481.

88 Franceschini G, Sirtori CR, Capurso A, et al: A-IMilano apoprotein: decreased high density lipoprotein cholesterol levels with significant lipoprotein modifications and without clinical atherosclerosis in an Italian family. J Clin Invest 1980;66:892-900.

89 Cerenis Therapeutics: CER-001 (Cerenis HDL). http://cerenis.com/pipeline_cer001. asp.

90 Bloedon L, Dunbar R, Duffy D, et al: Safety, pharmacokinetics, and pharmacodynamics of oral apoA-I mimetic peptide D-4F in highrisk cardiovascular patients. J Lipid Res 2008; 49:1344-1352.
91 Kaul S, Shah PK: ApoA-I Milano/phospholipid complexes emerging pharmacological strategies and medications for the prevention of atherosclerotic plaque progression. Curr Drug Targets Cardiovasc Haematol Disord 2005;5:471-479.

92 The Medicine Company: Pipeline. http:// www.themedicinescompany.com/page/ pipeline

93 Keyserling CH, Hunt TL, Klepp HM, et al: CER-001, a synthetic HDL-mimetic, safely mobilizes cholesterol in healthy dyslipidemic volunteers (abstract). Circulation 2011;124:A15525.

-94 Navab M, Anantharamaiah GM, Reddy ST, et al: Apolipoprotein A-I mimetic peptides. Arterioscler Thromb Vasc Biol 2005;25: 1325-1331.

-95 Anantharamaiah GM, Mishra VK, Garber DW, et al: Structural requirements for antioxidative and anti-inflammatory properties of apolipoprotein A-I mimetic peptides. J Lipid Res 2007;48:1915-1923.

-96 Navab M, Anantharamaiah GM, Reddy ST, et al: Apolipoprotein A-I mimetic peptides and their role in atherosclerosis prevention. Nat Clin Pract Cardiovasc Med 2006;3:540 547.

$\$ 97$ Ozasa H, Ayaori M, Iizuka M, et al: Pioglitazone enhances cholesterol efflux from macrophages by increasing ABCAl/ ABCG1 expressions via PPAR $\gamma / \mathrm{LXR} \alpha$ pathway: findings from in vitro and ex vivo studies. Atherosclerosis 2011;219:141-150.

98 Talbert RL: Hyperlipidemia; in DiPiro JT, Talbert RL, Yee GC, et al (eds): Pharmacotherapy: a Pathophysiologic Approach, ed 6. New York, McGraw-Hill, 2005.

99 Malloy MJ, Kane JP: Agents used in hyperlipidemia; in Katzung BG (ed): Basic and Clinical Pharmacology, ed 9. New York, McGraw-Hill, 2004, pp 561-575.

100 National Institutes of Health, National Heart, Lung, and Blood Institute: Third report of the National Cholesterol Education Program (NCEP) Expert Panel on Detection, Evaluation, and Treatment of High Blood Cholesterol in Adults (Adult Treatment Panel III) executive summary. NIH Publication 01-3670. Bethesda, NIH, 2001.

101 Graham DJ, Staffa JA, Shatin D, et al: Incidence of hospitalized rhabdomyolysis in patients treated with lipid-lowering drugs. JAMA 2004;292:2585-2590.

102 United States Food and Drug Administration: FDA expands advice on statin risk. http://www.fda.gov/ForConsumers/ConsumerUpdates/ucm293330.htm.

103 HDL LDL Cholesterol: Lowering Cholesterol Drugs Information On Their Effects. http://www.cholesterol-hdl-ldl.com/lowering-cholesterol-drugs.html.

104 WebMD: High cholesterol: cholesterollowering medication. http://www.webmd. $\mathrm{com} /$ cholesterol-management/guide/cholesterol-lowering-medication. 
105 American Heart Association: Drug therapy for cholesterol. http://www.heart.org/ HEARTORG/Conditions/Cholesterol/PreventionTreatmentofHighCholesterol/ Drug-Therapy-for-Cholesterol_ UCM_305632_Article.jsp.

106 Kotani K, Sakane N, Taniguchi N: Effect of ezetimibe on remnant-like particle cholesterol in subjects with metabolic syndrome. Med Princ Pract 2012;21:134-138.

107 Pearson TA, Laurora I, Chu H, et al: The lipid treatment assessment project (LTAP): a multicenter survey to evaluate the percentages of dyslipidemic patients receiving lipid-lowering therapy and achieving low-density lipoprotein cholesterol goals. Arch Intern Med 2000;160:459-467.

-108 Steinberg D, Witztum J: Inhibition of PCSK9: a powerful weapon for achieving ideal cholesterol levels. Proc Natl Acad Sci USA 2009;106:9546-9547.

109 Piper D, Jackson S, Liu Q, et al: The crystal structure of PCSK9: a regulator of plasma LDL-cholesterol. Structure 2007;15:545-552.

110 Naureckiene S, Ma L, Sreekumar K, et al: Functional characterization of Narc 1, a novel proteinase related to proteinase $\mathrm{K}$. Arch Biochem Biophys 2003;420:55-67.

-111 Abifadel M, Varret M, Rabès J, et al: Mutations in PCSK9 cause autosomal dominant hypercholesterolemia. Nat Genet 2003;34: 154-156.

$\$ 112$ Basak A: Inhibitors of proprotein convertases. J Mol Med 2005;83:844-855.

-113 Benjannet S, Rhainds D, Essalmani R, et al: NARC-1/PCSK9 and its natural mutants: zymogen cleavage and effects on the low density lipoprotein (LDL) receptor and LDL cholesterol. J Biol Chem 2004;279: 48865-48875.

114 Benjannet S, Rhainds D, Hamelin J, et al: The proprotein convertase PCSK9 is inactivated by furin and/or PC5/6A: functional consequences of natural mutations and post-translational modifications. J Biol Chem 2006;281:30561-30572.

-115 Cunningham D, Danley DE, Geoghegan KF, et al: Structural and biophysical studies of PCSK9 and its mutants linked to familial hypercholesterolemia. Nat Struct Mol Biol 2007;14:413-419.

-116 Pisciotta L, Priore Oliva C, Cefalu AB, et al: Additive effect of mutations in LDLR and PCSK9 genes on the phenotype of familial hypercholesterolemia. Atherosclerosis 2006;186:433-440.

117 Maxwell K, Breslow J: Adenoviral-mediated expression of PCSK9 in mice results in a low-density lipoprotein receptor knockout phenotype. Proc Natl Acad Sci USA 2004; 101:7100-7105.

118 Cohen J, Pertsemlidis A, Kotowski I, et al: Low LDL cholesterol in individuals of African descent resulting from frequent nonsense mutations in PCSK9. Nat Genet 2005; 37:161-165.
119 Rashid S, Curtis D, Garuti R, et al: Decreased plasma cholesterol and hypersensitivity to statins in mice lacking PCSK9. Proc Natl Acad Sci USA 2005;102:5374-5379.

120 Zhao Z, Tuakli-Wosornu Y, Lagace T, et al: Molecular characterization of loss-of-function mutations in PCSK9 and identification of a compound heterozygote. Am J Hum Genet 2006;79:514-523.

121 Li J, Tumanut C, Gavigan J-A, et al: Secreted PCSK9 promotes LDL receptor degradation independently of proteolytic activity. Biochem J 2007;406:203-207.

122 McNutt MC, Lagace TA, Horton JD: Catalytic activity is not required for secreted PCSK9 to reduce low density lipoprotein receptors in HepG2 cells. J Biol Chem 2007; 282:20799-20803.

123 Zhang D-W, Lagace TA, Garuti R, et al: Binding of proprotein convertase subtilisin/ kexin type 9 to epidermal growth factor-like repeat A of low density lipoprotein receptor decreases receptor recycling and increases degradation. J Biol Chem 2007;282:1860218612.

124 Kwon HJ, Lagace TA, McNutt MC, et al: Molecular basis for LDL receptor recognition by PCSK9. Proc Natl Acad Sci USA 2008;105:1820-1825.

125 Bottomley MJ, Cirillo A, Orsatti L, et al: Structural and biochemical characterization of the wild type PCSK9/EGF(AB) complex and natural familial hypercholesterolemia mutants. J Biol Chem 2009;284:13131323.

126 Seidah NG: PCSK9 as a therapeutic target of dyslipidemia. Expert Opin Ther Targets 2009;13:19-28.

127 Seidah NG, Prat A: The biology and therapeutic targeting of the proprotein convertases. Nat Rev Drug Discov 2012;11:367383.

128 Graham MJ, Lemonidis KM, Whipple CP, et al: Antisense inhibition of proprotein convertase subtilisin/kexin type 9 reduces serum LDL in hyperlipidemic mice. J Lipid Res 2007;48:763-767.

129 Lindholm MW, Elmen J, Fisker N, et al: PCSK9 RNA antisense oligonucleotides induce sustained reduction of LDL cholesterol in nonhuman primates. Mol Ther 2012; 20:376-381.

130 Frank-Kamenetsky M, Grefhorst A, Anderson NN, et al: Therapeutic RNAi targeting PCSK9 acutely lowers plasma cholesterol in rodents and LDL cholesterol in nonhuman primates. Proc Natl Acad Sci USA 2008; 105 : 11915-11920.

131 Seidah N, Benjannet S, Wickham L, et al: The secretory proprotein convertase neural apoptosis-regulated convertase 1 (NARC1) liver regeneration and neuronal differentiation. Proc Natl Acad Sci USA 2003;100: 928-933.
132 McNutt MC, Kwon HJ, Chen C, et al: Antagonism of secreted PCSK9 increases low density lipoprotein receptor expression in HepG2 cells. J Biol Chem 2009;284:1056110570.

133 Cohen J, Boerwinkle E, Mosley TH, et al: Sequence variations in PCSK9, low LDL, and protection against coronary heart disease. N Engl J Med 2006;354:1264-1272.

134 Duff CJ, Scott MJ, Kirby IT, et al: Antibodymediated disruption of the interaction between PCSK9 and the low density lipoprotein receptor. Biochem J 2009;419:577-584.

135 Chan JCY, Piper DE, Cao Q, et al: A proprotein convertase subtilisin/kexin type 9 neutralizing antibody reduces serum cholesterol in mice and nonhuman primates. Proc Natl Acad Sci USA 2009;106:9820-9825.

136 Liang H, Chaparro-Riggers J, Strop P, et al: Proprotein convertase substilisin/kexin type 9 antagonism reduces low-density lipoprotein cholesterol in statin-treated hypercholesterolemic nonhuman primates. J Pharmacol Exp Ther 2012;340:228-236.

137 Dias C, Shaywitz A, Smith B, et al: A phase 1 , randomized, double-blind, placebo-controlled, ascending single dose study to evaluate the safety, tolerability and pharmacodynamics of AMG145 (abstract). Circulation 2011;124:A10701.

138 Kohli P, Desai NR, Giugliano RP, et al: Design and rationale of the LAPLACE-TIMI 57 trial: a phase II, double-blind, placebocontrolled study of the efficacy and tolerability of a monoclonal antibody inhibitor of PCSK9 in subjects with hypercholesterolemia on background statin therapy. Clin Cardiol 2012;35:385-391.

139 Stein EA, Mellis S, Yancopoulos GD, et al: Effect of a monoclonal antibody to PCSK9 on LDL cholesterol. N Engl J Med 2012;366: 1108-1118.

140 McKenney J, Koren M, Kereiakes D, et al: Safety and efficacy of a monoclonal antibody to proprotein convertase subtilisin/ kexin type 9 serine protease, SAR236553/ REGN727, in patients with primary hypercholesterolemia receiving ongoing stable atorvastatin therapy. J Am Coll Cardiol 2012;59:2344-2353.

141 Sullivan D, Olsson AG, Scott R, et al: Effect of a monoclonal antibody to PCSK9 on lowdensity lipoprotein cholesterol levels in statin-intolerant patients: the GAUSS randomized trial. JAMA 2012;308:2497-2506.

142 Aegerion Pharmaceuticals Announces Oral Presentation of Phase III Lomitapide Data at European Atherosclerosis Society Conference. 2012. http://www.aegerion.com/.

143 Genzyme: Genzyme and Isis announce FDA approval of KYNAMRO ${ }^{\mathrm{TM}}$ (mipomersen sodium) injection for the treatment of homozygous familial hypercholesterolemia. http://news.genzyme.com/pressrelease/genzyme-and-isis-announce-fdaapproval-kynamro-mipomersen-sodiuminjection-treatment-h. 